\title{
Sustainable solutions for thermal energy saving in hospital operating theatres
}

\author{
Gonzalo Sánchez-Barroso Moreno ${ }^{1}$, Justo García-Sanz Calcedo ${ }^{2,}$, Alfonso G. González ${ }^{3}$, and David R. Salgado ${ }^{4}$ \\ ${ }^{1}$ University of Extremadura, Graphical Expression Department, Badajoz, Spain. \\ ${ }^{2}$ University of Extremadura, Graphical Expression Department, Badajoz, Spain. \\ ${ }^{3}$ University of Extremadura, Mechanical, Energy and Material Engineering Department, Mérida, Spain. \\ ${ }^{4}$ University of Extremadura, Mechanical, Energy and Material Engineering Department, Badajoz, Spain.
}

\begin{abstract}
Heating, ventilating and air conditioning systems in hospital operating theatres consume high amounts of energy, operate for long periods of time and provide high performance. For this reason, it is necessary to study their energy consumption and determine sustainable solutions that optimize their operation and improve their performance. In this paper, annual thermal energy consumption of a conventional operating theatre is evaluated. Potential energy savings is evaluated by maintaining an adequate indoor environmental quality for these rooms. In addition, how to minimize energy consumption depending on the air renewal flow rate used and installing a sensible heat recovery system was studied. Results show that energy demand of an operating room is reduced by $24.1 \%$ by recirculating $25 \%$ of air flow extracted from the room. Energy cost decreases $44.31 \%$ by increasing the recirculated air flow rate to $50 \%$ of the air flow extracted from the room.
\end{abstract}

\section{Introduction}

In Spain, 791 hospitals are operational [1], which house around 4,350 operating theatres [2] and consume $10 \%$ of the total energy consumed by the tertiary sector [3]. In UK, $30 \%$ of total public sector $\mathrm{CO}_{2}$ emissions were responsibility of hospitals [4]. The Australian Department of Health [5] concluded that hospital heating, ventilating and air conditioning systems (HVAC) consumed $67 \%$ of the total energy of the hospital and were responsible for $47 \%$ of total $\mathrm{CO}_{2}$ emissions to the atmosphere.

The average electrical energy consumption in a Spanish hospital for normal working conditions is 0.27 $\mathrm{MWh} / \mathrm{m}^{2}$. Specifically, the consumption of HVAC systems in Spanish hospitals accounts for $40 \%$ of their total consumption, with a value of $500 \mathrm{ktoe}$. Their savings potential is estimated to be between $45 \%$ and $55 \%$ thanks to investments with pay-back over 3 years [6]. So, operating theatres being one of the most energy-intensive facilities in hospitals.

In these buildings, HVAC systems are an effective way to control nosocomial infection of people inside the building caused by airborne bioparticles. On the other hand, Indoor Environmental Quality (IEQ) levels in both operating theatres and isolation rooms demand high technical performance from HVAC systems.

These technical performance features of HVAC systems are defined according to the levels of sepsis required to perform a surgical operation. In this respect, operating theatres fall into two categories [7]: Class I, high performance premises; and Class II, usual performance premises. In Class I operating theatres, more than $3,600 \mathrm{~m}^{3} / \mathrm{h}$ of ultra-clean air is driven through unidirectional flow system. In Class II operating theatres, more than $2,400 \mathrm{~m}^{3} / \mathrm{h}$ is driven through multidirectional flow system. In both types, at least $1,200 \mathrm{~m}^{3} / \mathrm{h}$ of external flow should be supplied.

By 2020, all publicly owned buildings should be classified as Nearly Zero Energy Buildings [8, 9]. The options for achieving these objectives are based, inter alia, on the use of renewable energy and/or waste and residual energy recovery equipment.

Smaller hospitals, as well as Health Centres, also have savings potential. García Sanz-Calcedo and Monzón González analysed the economic impact of environmental biosafety in Health Centre building projects and the measures to be used to minimize its impact on Health Centres in Extremadura (Spain) $[10,11]$.

Woods et al. (1986) presented a study to identify and verify nosocomial infection control strategies that could reduce energy consumption without compromising environmental quality within the operating room [12]. They observed a trend toward less sedimentation of viable bioparticles in the circulated air system and that thermal control for occupant comfort could affect sepsis control within the room.

Wang et al. (2012) carried out field measurements to evaluate the performance of an operating theatre with stand-by HVAC system [13]. The results showed that it can be achieved a satisfactory IEQ in the unoccupied

\footnotetext{
*Corresponding author: jgsanz@unex.es
} 
operating theatre by reducing the supply air volume (or speed) by $50 \%$. There is thus potential for energy savings by reducing the volume of supply air without increasing particle concentration or biocontamination.

Chen (2018) determined relevant design parameters of HVAC system, cold and heat sources configuration and fresh air supply routes to achieve energy savings [14]. Almost a third of the consumption can be saved by applying energy-saving design.

The aim of this study is to quantify thermal energy savings that can be achieved in a conventional operating theatre, by complementing installation of a sensible heat recovery system with the recirculation of air extracted from the room. In any case, the IEQ required will be maintained within these rooms to ensure the safety of the patient and medical staff.

\section{Methodology}

To determine the potential savings, electrical energy consumption of a conventional operating theatre (Class II) in standard operation was simulated during one year. Internal thermo-hygrometric conditions were established in accordance with the sanitary requirements. Thermal loads inside room and ventilation loads were then calculated. Subsequently, external thermo-hygrometric conditions were simulated according to historical values. Energy demand of an operating theatre for a given volumetric flow rate of supply air combined with different exterior air flow rates was then calculated. Moreover, the potential electrical energy and economic saving obtained through to use sensible heat recovery system was studied.

Defining indoor environmental conditions was conditioned by medical and cleaning needs required for clean rooms [15]. A high temperature value favours the sweating of people and proliferation of bacteria coloniesforming units. A very low temperature makes it difficult for human body to naturally pump oxygen to surgical wound, increasing the risk of infection. Therefore, the temperature ranges between $20^{\circ} \mathrm{C}$ and $24^{\circ} \mathrm{C}$ was established [7].

A value between $40 \%$ and $60 \%$ relative humidity is generally valid as it provides an acceptable level of comfort. Furthermore, it should be noted that microorganisms survive longer in extreme humidity conditions in both directions [7].

A minimum rate of 20 air changes per hour $(\mathrm{ACH})$ was considered according to airflow rate and volume of the room. Differential pressure with respect to adjacent rooms was established from $5 \mathrm{~Pa}$ to $20 \mathrm{~Pa}$ [15]. Over-pressured room is achieved by extracting by mechanical means a flow rate lower than supply flow rate. This will consolidate an operating room as a protected one and encourage the air movement from it to outdoors. Reference values for the key parameters of clean rooms HVAC system are given in Table 1.
Table 1. Reference values for key parameters.

\begin{tabular}{lc}
\multicolumn{1}{c}{ Parameter } & \multicolumn{1}{c}{ Value } \\
\hline Temperature & $20^{\circ} \mathrm{C}-24^{\circ} \mathrm{C}$ \\
\hline Relative humidity & $40 \%-60 \%$ \\
\hline \multirow{2}{*}{ Air change per hour } & Class I: $30 \mathrm{ACH}$ \\
& Class II: $20 \mathrm{ACH}$ \\
\hline \multirow{2}{*}{ Filtering levels } & Class I: F7 $+\mathrm{F} 9+\mathrm{H} 13$ \\
& Class II: F7+ F9 \\
\hline Pressurization & \multicolumn{1}{c}{$5 \mathrm{~Pa}-20 \mathrm{~Pa}$} \\
\hline
\end{tabular}

These conditions were applied to a Class II operating theatre. The dimensions of the room were: $6.00 \times 6.00 \mathrm{~m}$ and $2.85 \mathrm{~m}$ high, so we worked with a room of $36.00 \mathrm{~m}^{2}$ floor area and $102.60 \mathrm{~m}^{3}$ of volume. Centralized Air Handling Unit (AHU) systems were used, with an all-air, constant flow system that allows precise control of the thermo-hygrometric flow conditions for high flow rates. Thermal loads of the operating theatre were considered [16] caused by: lighting, occupation of 12 people and typical equipment, as shown in Table 2 . The loads due to heat transmission through walls were ignored since an operating theatre are rooms inside the hospital building whose adjacent rooms are also air-conditioned.

Table 2. Thermal loads considered.

\begin{tabular}{lrrr} 
& $\begin{array}{c}\text { Sensible Heat } \\
\left(\mathbf{W} / \mathbf{m}^{\mathbf{2}}\right)\end{array}$ & $\begin{array}{c}\text { Latent Heat } \\
\left(\mathbf{W} / \mathbf{m}^{\mathbf{2}}\right)\end{array}$ & $\begin{array}{c}\text { Total } \\
\left(\mathbf{W} / \mathbf{m}^{\mathbf{2}}\right)\end{array}$ \\
\hline Lighting & 23.70 & - & 23.70 \\
\hline Occupation & 861.60 & 546.00 & $1,407.60$ \\
\hline Equipment & $3,695.00$ & - & $3,695.00$ \\
\hline Total & $4,580.30$ & 546.00 & $5,126.30$ \\
\hline
\end{tabular}

Operating rooms does not operate at full-load during each hour of the day, so use factors of the room have been estimated as shown in the Table 3.

Table 3. Estimated use factors.

\begin{tabular}{|c|c|c|c|}
\hline Hour & Occupants & Lighting & Equipment \\
\hline 01:00 & $10 \%$ & $10 \%$ & $50 \%$ \\
\hline 02:00 & $10 \%$ & $10 \%$ & $50 \%$ \\
\hline 03:00 & $10 \%$ & $10 \%$ & $50 \%$ \\
\hline 04:00 & $10 \%$ & $10 \%$ & $50 \%$ \\
\hline 05:00 & $10 \%$ & $10 \%$ & $50 \%$ \\
\hline 06:00 & $10 \%$ & $10 \%$ & $50 \%$ \\
\hline 07:00 & $50 \%$ & $50 \%$ & $50 \%$ \\
\hline 08:00 & $100 \%$ & $100 \%$ & $100 \%$ \\
\hline 09:00 & $100 \%$ & $100 \%$ & $100 \%$ \\
\hline $10: 00$ & $100 \%$ & $100 \%$ & $100 \%$ \\
\hline $11: 00$ & $100 \%$ & $100 \%$ & $100 \%$ \\
\hline $12: 00$ & $100 \%$ & $100 \%$ & $100 \%$ \\
\hline $13: 00$ & $100 \%$ & $100 \%$ & $100 \%$ \\
\hline $14: 00$ & $100 \%$ & $100 \%$ & $100 \%$ \\
\hline $15: 00$ & $100 \%$ & $100 \%$ & $100 \%$ \\
\hline $16: 00$ & $100 \%$ & $100 \%$ & $100 \%$ \\
\hline $17: 00$ & $100 \%$ & $100 \%$ & $100 \%$ \\
\hline $18: 00$ & $100 \%$ & $100 \%$ & $100 \%$ \\
\hline 19:00 & $100 \%$ & $100 \%$ & $100 \%$ \\
\hline 20:00 & $50 \%$ & $50 \%$ & $50 \%$ \\
\hline 21:00 & $50 \%$ & $50 \%$ & $50 \%$ \\
\hline $22: 00$ & $10 \%$ & $30 \%$ & $50 \%$ \\
\hline 23:00 & $10 \%$ & $10 \%$ & $50 \%$ \\
\hline
\end{tabular}


Thermal loads of ventilation were calculated for each hour of the day of every day of the year. The indoor conditions planned for the room are: Temperature, $\mathrm{T}_{\mathrm{L}}=$ $22^{\circ} \mathrm{C}$, Relative Humidity, $\mathrm{RH}_{\mathrm{L}}=50 \%$, Enthalpy, $\mathrm{H}_{\mathrm{L}}=$ $10.5 \mathrm{kcal} / \mathrm{kg}$ y specific humidity, $\mu_{\mathrm{L}}=8.5 \mathrm{gH}_{2} \mathrm{O} / \mathrm{kg}$ air. The external conditions are referenced to the location in Badajoz (Spain) [17].

Calculation hypotheses are shown in Table 4. Initially, the base case (Case I) of a conventional operating theatre with an air flow rate of $2,400 \mathrm{~m}^{3} / \mathrm{h}$ is presented. The entire air flow comes from the outside. On this basis, the proposed energy demand reduction strategies were implemented and their performance was quantified both energetically and economically. In Case II, the installation of a sensible heat recovery system was studied. In Case III, the recirculation strategy of $25 \%$ of the local exhaust flow was used. In Case IV, the heat recovery system was combined with the recirculation of $25 \%$ of the air flow extracted from the room. In Case $\mathrm{V}$, the consumption was studied when $50 \%$ of the air flow extracted from the room is recirculated. Finally, Case VI combined the recirculation of $50 \%$ of the room flow with the installation of a sensible heat recovery unit. For these cases, a 52\% efficiency sensible heat recovery equipment, $\varepsilon$, was used. [18].

Table 4. Calculation hypotheses.

\begin{tabular}{|c|c|c|c|}
\hline & $V_{\text {imp }}\left(m^{3} / \mathbf{h}\right)$ & $V_{\text {outside }}\left(\mathbf{m}^{3} / \mathbf{h}\right)$ & $\varepsilon$ \\
\hline Case I & 2,400 & 2,400 & - \\
\hline Case II & 2,400 & 2,400 & $52 \%$ \\
\hline Case III & 2,400 & 1,800 & - \\
\hline Case IV & 2,400 & 1,800 & $52 \%$ \\
\hline Case V & 2,400 & 1,200 & - \\
\hline Case VI & 2,400 & 1,200 & $52 \%$ \\
\hline
\end{tabular}

Operation of each hypothesis was simulated for each hour of the day based on the estimated use factor of the room for each day of the year. In this way, very precise results were obtained on the annual energy demand of the installation, the economic cost of operation, its potential for electrical energy and monetary savings, as well as the amount of $\mathrm{CO}_{2}$ emitted into the atmosphere.

\section{Results}

Thermal loads profile during a day to be beaten in the operating room is repeated daily as a similar daily use of the facilities is envisaged. Thermal loads profile is calculated as a conjunction of the room thermal and ventilation loads for each hour of the day depending on the hourly usage factor.

Fig. 1 shows the daily sensible thermal load profile to which the operating room is subjected. The latent thermal load profile is shown in Fig. 2.

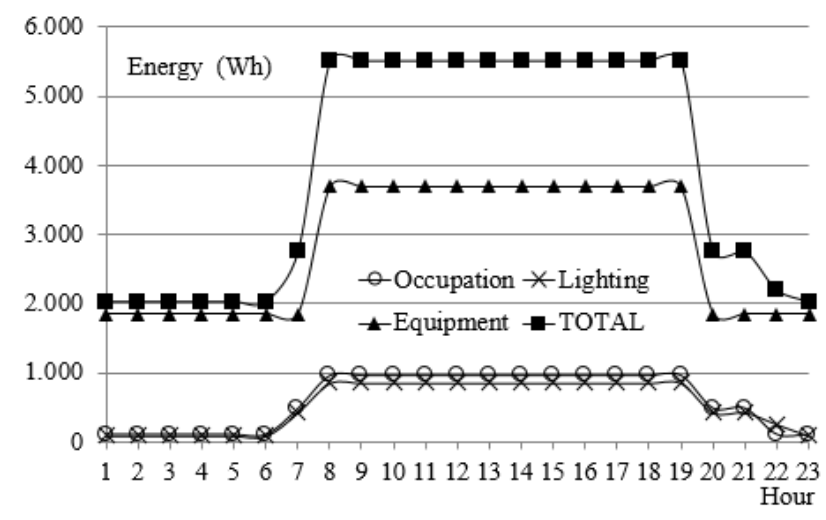

Fig. 1. Daily sensible thermal load profile.

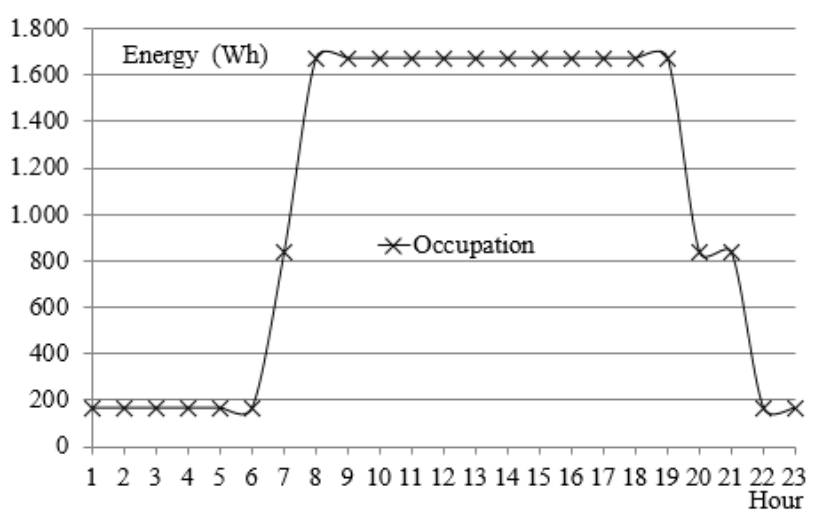

Fig. 2. Daily latent thermal load profile.

Table 5 shows the results with energy and environmental implications for each of the working hypotheses proposed. These allow to evaluate the potential savings achieved by installing the sensible heat recovery system and/or recirculating air extracted from the room. For this purpose, results obtained for each Case $n$ (where $n=\mathrm{II}-\mathrm{VI}$ ) are compared with the base case (Case I). In addition, the amount of $\mathrm{CO}_{2}$ emitted into the atmosphere is calculated according to its equivalent to Spanish electrical energy [18].

Table 5. Energy and environmental results of sensible heat recovery unit installation.

\begin{tabular}{lrrr} 
& $\begin{array}{c}\text { Energy } \\
\text { (kWh/year) }\end{array}$ & $\begin{array}{c}\text { Save } \\
\text { (kWh/year) }\end{array}$ & $\begin{array}{c}\text { Emission } \\
\text { (ton CO2) }\end{array}$ \\
\hline Case I & $88,490.87$ & 0.00 & $57,430.57$ \\
\hline Case II & $65,201.87$ & $23,289.00$ & $42,316.01$ \\
\hline Case III & $67,173.95$ & $21,316.92$ & $43,595.89$ \\
\hline Case IV & $51,263.07$ & $37,227.80$ & $33,269.73$ \\
\hline Case V & $47,279.18$ & $41,211.69$ & $30,684.19$ \\
\hline Case VI & $39,228.93$ & $49,261.94$ & $25,459.58$ \\
\hline
\end{tabular}

Table 6 shows the operating costs related to each of the cases presented. In addition, the monetary savings involved in implementing each savings solutions are quantified. The results of the monetary cost of operating the HVAC system consider an electricity cost of 0.15 $€ /$ kWh. 
Table 6. Economic results of sensible heat recovery unit installation.

\begin{tabular}{lrr} 
& Cost $(\boldsymbol{\epsilon} /$ year) & Save $(\boldsymbol{\epsilon} /$ year) \\
\hline Case I & $13,273.63$ & 0.00 \\
\hline Case II & $9,780.28$ & $3,493.35$ \\
\hline Case III & $10,076.09$ & $3,197.54$ \\
\hline Case IV & $7,689.46$ & $5,584.17$ \\
\hline Case V & $7,091.88$ & $6,181.75$ \\
\hline Case VI & $5,884.34$ & $7,389.29$ \\
\hline
\end{tabular}

\section{Discussion}

Installing a sensible heat recovery system and returning part of the airflow extracted from the room reduces energy demand of an operating theatre. Both strategies reduce the power required by the AHU to reach the thermohygrometric conditions of the supply air to the room.

Spanish regulations require energy to be recovered from the exhaust air when the air flow extracted by mechanical means exceeds $1,800 \mathrm{~m}^{3} / \mathrm{h}$ [19]. Therefore, in all cases it is mandatory to install an energy recovery system, like sensible heat recovery unit.

The installation of the sensible heat recovery system (Case II) represents a saving of $26.32 \%$ compared to Case I. If $25 \%$ of the air flow extracted from the room is recirculated (Case III), an amount similar to the saving $(24.1 \%)$ is obtained. If both solutions are combined (Case IV), the savings are greatly increased. In that case, the system requires $42.1 \%$ less energy. If the recirculated air flow is increased to $50 \%$ (Case V), the results are similar to Case IV (44.31\%). The optimum result is obtained for Case VI with a $55.67 \%$ saving.

On the other hand, the operating cost of the operating room decreases from $3,493.35 €$ for Case II to 7,389.29€ for Case VI, as compared to Case I with 13,273.63 €. In addition, savings in operating costs have been obtained due to the increase in air recirculation capacity. Both terms should be compared with the cost of the investment required to install the recirculation ducts and/or the sensible heat recovery unit, as necessary, to assess the economic viability of the investment.

Between 15 and 30 tons of $\mathrm{CO}_{2}$ equivalent are avoided by applying these sustainable solutions. Therefore, the investment is also environmentally beneficial.

The results show that this type of study favours the optimization of the design solution of an operating room. This will ensure adequate ventilation quality to minimise the risk of nosocomial infection and optimise energy and environmental costs [20].

\section{Conclusions}

It was determined that the energy demand of the operating room was reduced $24.10 \%$ by recirculating $25 \%$ of the air flow extracted from the room. Energy cost decreases by $44.31 \%$ by increasing the recirculated air flow rate to $50 \%$ of the air flow extracted from the room. The highest savings value is achieved by installing the sensible heat recovery unit and recirculating $50 \%$ of the air flow extracted from the room. This saving would represent $55.67 \%$ in the energy demand of the operating room.

Both solutions have been shown to provide results that reduce energy demand due to ventilation loads. Besides, they are also compatible. Working in a complementary way provides a significant improvement of the results. They allow to reduce the energy and economic cost of operation while maintaining Indoor Environmental Quality required in the operating rooms [21].

The authors wish to acknowledge to the Junta de Extremadura and the European Social Found (FEDER) for the support of this research work. This study has been carried out through the Research Project GR-18029 linked to the VI Regional Plan for Research, Technological Development and Innovation from the General Government of Extremadura 2017-2020.

\section{References}

1. Annual Report of the National Health System 2016, Ministry of Health, Social Services and Equality (2016).

2. The Spanish Health System in numbers, Circle of Health (2016).

3. Annual Report on Energy Consumption, Institute for Energy Diversification and Saving (2015).

4. C. A. Short, K. J. Lomas, R. Giridharan, and A. J. Fair, Building resilience to overheating into 1960's UK hospital buildings within the constraint of the national carbon reduction target: Adaptive strategies, Build. Environ., 55, 73-95 (2012).

5. Department of Health. Sustainability in healthcare 2012, Victoria Department of Health (2017).

6. A. Cuchi and P. Sweatmen, Estrategia para la rehabilitación. Claves para transformar el sector de la edificación en España, GTR 2013. INFORME GTR (2014).

7. UNE 100713:2015 Air conditioning in hospitals. AENOR 2015.

8. Commission of the European Communities (2009). White Paper Adapting to climate change: Towards a European framework for action. Brussels: Commission of the European Communities.

9. Directive 2012/27/EU of the European Parliament and of the Council of 25 October 2012 on energy efficiency.

10. J. García Sanz-Calcedo, P. Monzón González. Analysis of the economic impact of environmental biosafety works projects in healthcare centres in Extremadura (Spain), DYNA 81, 100-105 (2014).

11. P. Monzón González, J. García Sanz-Calcedo, F. D. Fernández, M. V. Domínguez, Gestión de la bioseguridad ambiental en fase de proyecto de obras en recintos hospitalarios. Todo Hospital, 277, 9-20 (2012).

12. J. E. Woods, D. T. Brayman, R. W. Rasmussen, G. L. Reynolds, and G. M. Montag. Ventilation requirements in hospital operating rooms - Part I: 
Control of airborne particles. ASHRAE Tran., 92, 396-426 (1986).

13. F. J. Wang, T. B. Chang, C. M. Lai, Z.Y. Liu. Performance improvement of airflow distribution and contamination control for an unoccupied operating room, in International Building Performance Simulation Association, Taiwan (2012).

14. Y. Chen. Study on energy-saving design and operation of hospital purification air conditioning system. International Journal of Low-Carbon Technologies 13, 184-190 (2018).

15. ISO 14644-4:2001 Cleanrooms and associated controlled environments. Part 4: Design, construction and start-up.

16. ASHRAE, HVAC Design Manual for Hospitals and Clinics, ASHRAE (2013).
17. Technical guide: External project conditions, Institute for Energy Diversification and Saving (2010).

18. Yearbook of Air Conditioning and Refrigeration 2017, Spanish Technical Association of AirConditioning and Refrigeration (2018).

19. Spanish Royal Decree 1027/2007. Regulation on Thermal Installations in Buildings.

20. A. González-González, J. Garcia-Sanz-Calcedo, D. Rodriguez-Salgado. Evaluation of energy consumption in German hospitals: benchmarking in the public sector. Energies, 11, 2279 (2018).

21. J. García-Sanz-Calcedo, M. Gómez Chaparro. Quantitative Analysis of the Impact of Maintenance Management on the Energy Consumption of a Hospital in Extremadura (Spain), Sustainable Cities and Society 30, 217-222 (2017). 